\title{
Synthetic materials in art: a new comprehensive approach for the characterization of multi-material artworks by analytical pyrolysis
}

\author{
Jacopo La Nasa, Greta Biale, Francesca Sabatini, Ilaria Degano, Maria Perla Colombini \\ and Francesca Modugno* ${ }^{*}$
}

\begin{abstract}
Modern art materials introduced since the end of XIX century include a large number of formulations of synthetic polymers and pigments, whose degradation processes and best preservation conditions are a major issue in heritage science. Analytical pyrolysis coupled with gas chromatography and mass spectrometry (Py-GC/MS) is widely used for the characterisation of polymeric materials and organic pigments, however the interpretation of the pyrograms obtained from samples containing different analytes is not straightforward. To improve our understanding on how these materials behave in complex matrices, we used evolved gas analysis coupled with mass spectrometry (EGA-MS) and multi shot Py-GC/MS to highlight and analyse the different fractions in a sample from a pop-art made of painted polyurethane (PU) foam. The study represents a proof of concept to evaluate EGA-MS potential in studying composite modern art materials in combination with multi-shot pyrolysis. The aim of the investigation was establishing the composition of the PU formulation, the paint binder and the pigments, thereby contributing to planning the stabilisation and conservation of the object. The polymers and the class of synthetic organic pigments present in the paint were assessed by determining their specific pyrolysis products and through comparisons with data in the literature. EGA-MS analysis provided both thermal and chemical information in one analytical run, so that we could select four temperatures for use in multi-shot Py-GC/MS analysis and thus to selectively study the different fractions evolved at different temperatures. Information on the various components of the mixture was obtained, including additives and organic pigments, separating them on the basis of their different thermal degradation temperatures. The multianaIytical approach included also non-destructive ATR-FTIR and enabled us to characterize in detail different synthetic materials: polyether-based polyurethane produced by the polyaddition of 2,6-diisocyanate toluene, hexamethylene diisocyanate and polypropylene glycol, vinyl paint, and a mixture of $\beta$-naphthol and mono-azo as pigments. HPLCDAD and HPLC-ESI-MS analyses confirmed the pigments, and provided a positive identification of two $\beta$-naphthols (PO5 and PR1) and two monoazo pigments (PY1 and PY3).
\end{abstract}

Keywords: Modern artistic materials, Polyurethane foam, Synthetic organic pigments, Py-GC/MS, EGA-MS, HPLCDAD-ESI-MS

*Correspondence: francesca.modugno@unipi.it

Department of Chemistry and Industrial Chemistry, University of Pisa, Via

Giuseppe Moruzzi, 13, Pisa 56124, Italy 


\section{Introduction}

Preserving modern and contemporary artworks and design objects is emerging as a major issue in conservation science, due to the wide range of new techniques and materials for artists that have been introduced since the end of the nineteenth century $[1,2]$. Modern art materials include a large number of formulations of synthetic polymers and pigments whose degradation processes and optimal preservation conditions are far from being fully assessed.

In addition, the combination of more than one material in the same artwork makes the conservation of synthetic polymers in heritage objects a critical issue, due to possible interactions between components, which are characterized by different degradation pathways and a different durability. In particular, some classes of synthetic organic pigments (SOPs) are labile and vulnerable to fading and photo-oxidation phenomena [3]. The knowledge of their exact composition, in terms of both major and minor components, is mandatory to disclose the chemical behaviour of a specific SOP over time [4].

Correctly identifying modern artistic materials also represents a challenge for chemical analysis, especially for composite objects. The identification of organic pigments is further complicated by the lack of information generated by their generic trade names and by the frequent commercialization of the same compound under different names and vice versa; moreover, scarce attention was often paid to the purification steps [5].

FTIR spectroscopy is one of the most common approaches used to identify synthetic polymers in heritage objects [6-11]. However, its effectiveness is dramatically reduced when studying samples constituted by a mixture of materials. Pyrolysis coupled with gas chromatography and mass spectroscopy (Py-GC/MS) has proven fundamental in the chemical analysis of synthetic polymers [12-23] and SOPs [16, 24]. Unfortunately, the identification of dyes and pigments is based on the detection of specific pyrolysis products, which are often insufficient to assess the exact molecular formula of the pigment under study. Moreover, due to patent wars, several synthetic strategies were proposed for the production of analogue dyes or pigments [25] and the presence of synthesis by-products, which might provide insights on the provenance of the colouring material, can hardly be assessed by Py-GC/MS. A more in-depth characterisation can only be obtained by using liquid chromatography with high resolution mass spectrometry (HPLC-MS), which is able to identify the intact coloured molecules present both as major and minor components of the pigment [26, 27].

In the last 10 years multi-shot pyrolysis-gas chromatography/mass spectrometry (Py-GC/MS) has been applied to maximize the information obtained from the analysis of single samples containing different components with a wide range of molecular weights [12, 28]. In heritage science, Py-GC/MS has been used for identifying and discriminating between the additives used in the production of synthetic paints and for investigating degradation processes [20, 21, 29].

The information obtained by a combination of thermal and chemical analyses can be further improved by using evolved gas analysis-mass spectrometry (EGAMS). Integrating multi-shot Py-GC/MS with EGA-MS data significantly increases the selectivity of the chemical information of pyrolysis-based approaches. Evolved gas analysis can be applied to characterise the thermal profile of a sample, and the data obtained can be used to optimize the temperatures used in multi shots Py-GC/MS analysis [12].

To date, EGA-MS has been mainly used to study reference materials in order to rationalize degradation pathways, or to disclose the nature of interactions occurring in composite materials, however it also provides insights into the nature and degradation of unknown samples [29-31].

This study further explores the advantages of introducing EGA-MS in the field of heritage science and examine its potential in combination with multi-shot pyrolysis to investigate modern artistic materials. As a proof of concept to evaluate the approach, here we present the results obtained in the investigation of a sample from painted polyurethane (PU) foam. The sample was collected from the pop-art sculpture "Disgelo" (1968, painted polyurethane foam, $440 \mathrm{~cm} \times 99 \mathrm{~cm}$ ), by the Italian artist Piero Gilardi (1942). The artwork belongs to the series of "Tappeti Natura" (Nature Carpets), which are detailed and realistic copies of patches of natural landscapes made in polyurethane flexible foam, colourfully painted with great detail to achieve a hyperrealistic and synthetic reproduction of nature (Fig. 1) [32, 33].

The preservation and stabilisation of $\mathrm{PU}$ artworks in the conservation of modern art from the 1960s is extremely challenging [34]. The aim of the investigation was establishing the composition of the PU formulation, the paint binder and the pigments, and thereby contributing to planning the stabilisation and conservation of the object for future accessibility.

EGA-MS was applied to evaluate the thermal profile of the sample and to optimize the pyrolysis temperatures for the subsequent application of multi shot Py-GC/MS in order to separately analyse the different components of the sample.

Finally, high-performance liquid chromatography with diode-array and mass spectrometric detection (HPLC-DAD and HPLC-DAD-ESI-MS) and infrared 

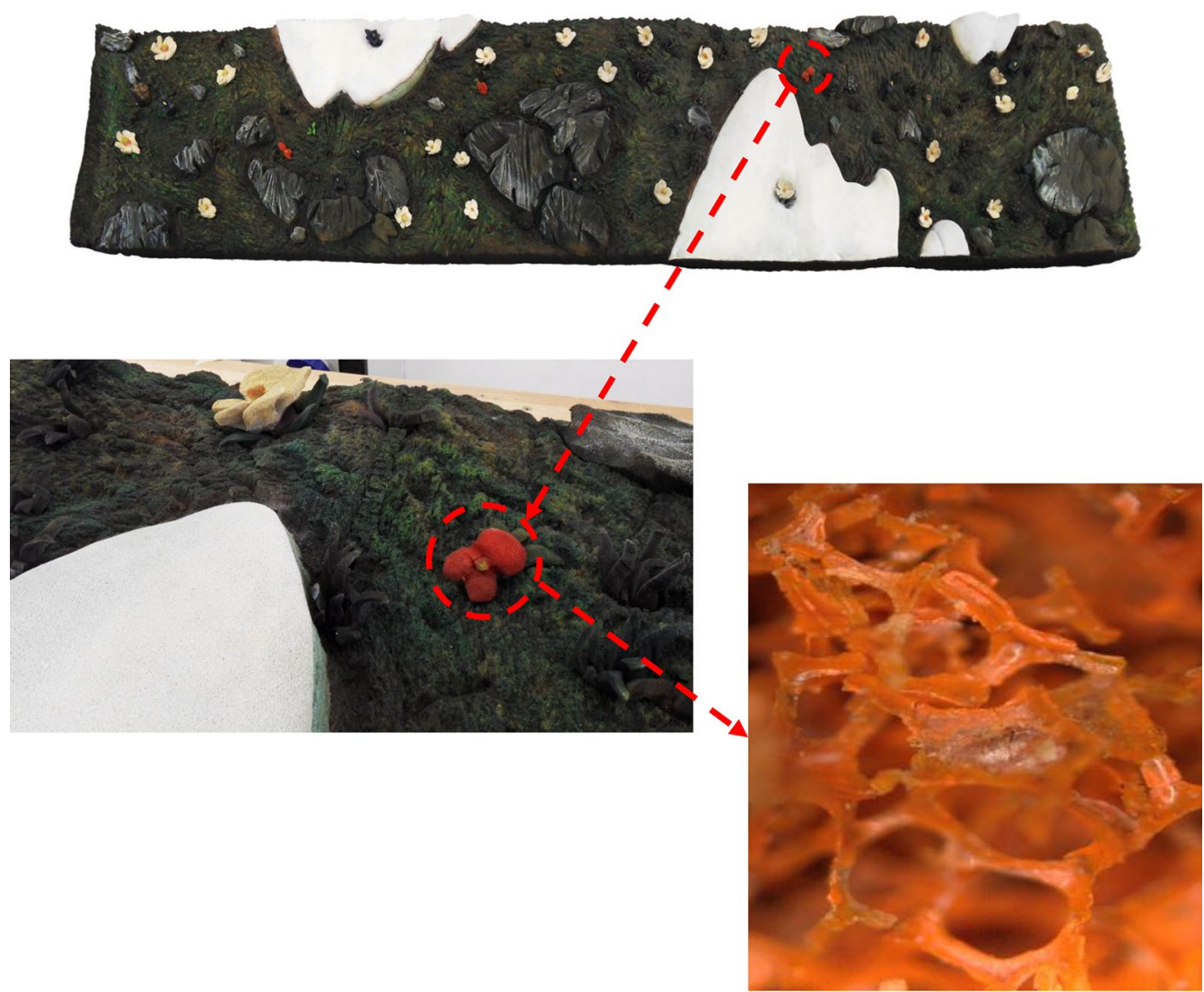

Fig. 1 "Disgelo" (1968) by Italian artist Piero Gilardi (1942). Optical microscopy detail of the polymeric network

spectroscopy analyses were performed to integrate the results obtained by pyrolysis-based methods [35].

The evaluation of the adopted micro-destructive analytical approach was particularly interesting in this case where non-destructive spectroscopic techniques commonly used to investigate heritage objects (such as portable non-invasive FTIR and Raman spectroscopy) were not applicable, due to the highly porous nature of the polyurethane foam, the complex mixture of components, and the presence of a surface paint layer.

\section{Materials and methods}

\section{Materials and samples investigated}

The sample, DG1, characterized by a bright red colour, was collected by the restorer Antonio Rava during some conservation of the artwork, planned prior to the exhibition "Nature Forever. Piero Gilardi" (April to October 2017) at the Maxxi Museum in Rome [32]. The weight of the sample was $1.5 \mathrm{~g}$.

\section{Attenuated total reflectance infrared spectroscopy (ATR-FTIR)}

ATR-FTIR spectra were collected directly on fragments of foam using a Perkin Elmer Spectrum 100 spectrometer coupled with a MIRacle TM ATR accessory equipped with a SeZn crystal. Sixteen scans were collected from 4000 to $650 \mathrm{~cm}^{-1}$ with a resolution of $4 \mathrm{~cm}^{-1}$. The analyses were performed at room temperature $\left(22^{\circ} \mathrm{C}\right)$. Jasco Spectra Manager software was used for data analysis.

\section{Evolved gas analysis-mass spectrometry}

The samples were placed into a pyrolysis stainless-steel cup, weighed $(500 \mu \mathrm{g})$, and inserted into the microfurnace. The instrumentation consisted of a micro-furnace Multi-Shot Pyrolyzer EGA/Py-3030D (Frontier Lab, Japan) connected to an Agilent 5973 single quadrupole Mass Selective Detector through an Ultra ALLOY ${ }^{\circledR}$ EGA Tube $(2.5 \mathrm{~m} \times 0.15 \mathrm{~mm}$ i.d). The EGA-tube was thermostated at $300{ }^{\circ} \mathrm{C}$ inside the oven of a $6890 \mathrm{~N}$ gas chromatographic system (Agilent Technologies). 
The temperature program for the micro-furnace chamber of the pyrolyzer was as follows: initial temperature $50{ }^{\circ} \mathrm{C} ; 10{ }^{\circ} \mathrm{C} / \mathrm{min}$ up to $800{ }^{\circ} \mathrm{C}$ for $10 \mathrm{~min}$. Analyses were performed under a helium gas (purity $99.9995 \%)$ flow $(1 \mathrm{ml} / \mathrm{min})$ with a split ratio $1: 20$. The micro-furnace interface temperature was automatically kept at $100{ }^{\circ} \mathrm{C}$ higher than the furnace temperature up to a maximum value of $300{ }^{\circ} \mathrm{C}$. The inlet temperature was $280{ }^{\circ} \mathrm{C}$. The mass spectrometer was operated in EI positive mode $(70 \mathrm{eV}$, scanning $\mathrm{m} / \mathrm{z} 50-700)$. The MS transfer line temperature was $300{ }^{\circ} \mathrm{C}$. The MS ion source temperature was kept at $230{ }^{\circ} \mathrm{C}$, and the MS quadrupole temperature at $150{ }^{\circ} \mathrm{C}$.

\section{Multi-shot pyrolysis-gas chromatography/mass spectrometry}

Analyses were performed using the same multi-shot pyrolyzer EGA/PY-3030D (Frontier Lab) mentioned in "Evolved gas analysis-mass spectrometry" section, coupled with the $6890 \mathrm{~N}$ gas chromatographic system with a split/splitless injection port, and with the above mentioned 5973 mass selective single quadrupole mass spectrometer (both Agilent Technologies) [36].

Multi-shot pyrolysis conditions were optimized as follows. Pyrolysis temperatures were selected based on the specific EGA/MS results ("Py-GC/MS" section): shot 1 : $260{ }^{\circ} \mathrm{C}$; shot 2: $308{ }^{\circ} \mathrm{C}$; shot 3: $340{ }^{\circ} \mathrm{C}$; shot $4: 600{ }^{\circ} \mathrm{C}$. The interface and the $\mathrm{GC}$ injector were kept at $280^{\circ} \mathrm{C}$. The GC injection was operated in split mode, with a split ratio of 1:10. The chromatographic separation of pyrolysis products was performed on a fused silica capillary column HP-5MS (5\% diphenyl-95\% dimethyl-polysiloxane, $30 \mathrm{~m} \times 0.25 \mathrm{~mm}$ i.d., $0.25 \mu \mathrm{m}$ film thickness, J\&W Scientific, Agilent Technologies), preceded by $2 \mathrm{~m}$ of deactivated fused silica pre-column with an internal diameter of $0.32 \mathrm{~mm}$. The chromatographic conditions were: $40{ }^{\circ} \mathrm{C}$ for $5 \mathrm{~min}, 10{ }^{\circ} \mathrm{C} / \mathrm{min}$ to $310{ }^{\circ} \mathrm{C}$ for $20 \mathrm{~min}$. The helium (purity 99.9995\%) gas flow was set in constant flow mode at $1.2 \mathrm{ml} / \mathrm{min}[13,14,17-19,37]$.

MS parameters: electron impact ionization (EI, $70 \mathrm{eV}$ ) in positive mode; ion source temperature $230{ }^{\circ} \mathrm{C}$; scan range $50-700 \mathrm{~m} / \mathrm{z}$; interface temperature $280{ }^{\circ} \mathrm{C}$. Perfluorotributylamine (PFTBA) was used for mass spectrometer tuning. MSD ChemStation (Agilent Technologies) software was used for data analysis and the peak assignment was based on a comparison with libraries of mass spectra (NIST 1.7, WILEY275) and the literature data [38].

Prior to each analysis sequence, the pyrolysis cup was cleaned and a blank was run by inserting in the pyrolysis cup $2 \mu \mathrm{l}$ of hexamethyldisilazane (HMDS, Sigma-Aldrich, USA) as derivatizing agent.
High performance liquid chromatography with diode array detector (HPLC-DAD) and high performance liquid chromatography with high resolution mass spectrometric detection (HPLC-ESI-Q-ToF)

HPLC was performed to investigate the organic pigments contained in the sample. The method is a slight adaptation of a previously published method used to study reference synthetic organic dyes and pigments [4]. The sample pre-treatment prior to both chromatographic analyses consisted in the addition of $500 \mu$ l of dimethyl sulfoxide to approximately $850 \mu \mathrm{g}$ of sample, followed by sonication (ultrasonic bath Sonorex Supra 10P, Bandelin Electronics, Germany) for $10 \mathrm{~min}$ at $60{ }^{\circ} \mathrm{C}$. The supernatant was filtered with a PTFE syringe filter, and directly injected into the chromatographic system. The injection volume was $10 \mu \mathrm{L}$.

The HPLC system consists of a PU-2089 quaternary pump equipped with a degasser, an AS-950 autosampler, and an MD-2010 spectrophotometric diode array detector (all modules are Jasco International Co., Japan). The diode array detector (DAD) operated with spectra acquisition in the range of 200-650 nm every $0.8 \mathrm{~s}$ with $4 \mathrm{~nm}$ resolution. ChromNav software was used to carry out data acquisition and data analysis.

An HPLC 1200 Infinity was used, coupled with a quadrupole-time of flight mass spectrometer Infinity Q-ToF 6530 detector by a Jet Stream ESI interface (Agilent Technologies, USA). ESI conditions were: drying and sheath gas $\mathrm{N}_{2}$, purity $>98 \%$, temperature $350{ }^{\circ} \mathrm{C}$, flow $10 \mathrm{l} / \mathrm{min}$ and temperature $375{ }^{\circ} \mathrm{C}$, flow $11 \mathrm{l} / \mathrm{min}$, respectively; capillary voltage $4.5 \mathrm{kV}$; nebulizer gas pressure $35 \mathrm{psi}$. The high resolution MS and MS/MS acquisition range was set from 100 to $1000 \mathrm{~m} / \mathrm{z}$ in negative mode, with acquisition rate 1.04 spectra/s. For the MS/MS experiments, $30 \mathrm{~V}$ were applied in the collision cell to obtain CID fragmentation (collision gas $\mathrm{N}_{2}$, purity $99.999 \%$ ). The FWHM (full width half maximum) of quadrupole mass bandpass used during MS/MS precursor isolation was $4 \mathrm{~m} / \mathrm{z}$. The Agilent tuning mix HP0321 was used daily to calibrate the mass axis. MassHunter Workstation Software (B.04.00) was used for both data acquisition and data analysis.

The eluents for the HPLC-DAD analyses were: water and acetonitrile (ACN) both HPLC grade (Sigma Aldrich, USA), while the eluents for HPLC-ESI-Q-ToF analyses were water and acetonitrile, both LC-MS grade (Sigma-Aldrich, USA). All eluents were added with 0.1\% $\mathrm{v} / \mathrm{v}$ formic acid (FA; $98 \%$ purity, J.T. Baker, USA). The chromatographic separation was performed on an analytical reversed-phase column Poroshell 120 EC-C18 $(3.0 \times 75 \mathrm{~mm}$, particle size $2.7 \mu \mathrm{m})$ with a Zorbax SB-C18 pre-column $(4.6 \times 12.5 \mathrm{~mm}$, particle size $5 \mu \mathrm{m})$, both Agilent Technologies. The flow rate was $0.4 \mathrm{ml} / \mathrm{min}$ and the program was $15 \% \mathrm{~B}$ for $2.6 \mathrm{~min}$, then to $50 \% \mathrm{~B}$ in 
$13.0 \mathrm{~min}$, to $70 \% \mathrm{~B}$ in $5.2 \mathrm{~min}$, to $100 \% \mathrm{~B}$ in $0.5 \mathrm{~min}$ and then held for $6.7 \mathrm{~min}$. Re-equilibration took $11 \mathrm{~min}$. During the separation, the column was kept at $30{ }^{\circ} \mathrm{C}$.

\section{Results and discussion ATR-FTIR}

Figure 2 shows the ATR-FTIR spectrum of the sample. Table 1 reports the identification of the observed ATRFTIR bands [20, 39-43]. The spectrum shows the presence of a polyether-based polyurethane on the basis of the stretching vibration of $\mathrm{C}-\mathrm{O}-\mathrm{C}$ at $1093 \mathrm{~cm}^{-1}$. Absorption bands typical of hydrogen bond interactions were observed: $\mathrm{N}-\mathrm{H}$ stretching at $3661-3303 \mathrm{~cm}^{-1}$ (H-bonded and non $\mathrm{H}$-bonded) and in the carbonyl region (1740-1640 $\mathrm{cm}^{-1}$ ), with a stretching vibration corresponding to that of the $\mathrm{H}$-bonded urea at $\sim 1641 \mathrm{~cm}^{-1}$. The formation of free urea is a sign of the cleavage of urethane bonds [40, 44], suggesting an ongoing depolymerisation process in the material.

Two intense absorption bands were observed at $1731 \mathrm{~cm}^{-1}$ and at $1226 \mathrm{~cm}^{-1}$, which may be related to the stretching vibration of the ester carbonyl group $(\mathrm{C}=\mathrm{O})$ and the stretching vibration of ester $\mathrm{C}-\mathrm{O}-\mathrm{C}=\mathrm{O}$ group, respectively. This suggests that a polyester was present in the paint formulation.

Other significant absorption bands were: the $-\mathrm{C}-\mathrm{H}_{2}$ and $-\mathrm{C}-\mathrm{H}_{3}$ stretching (2970-2950 $\mathrm{cm}^{-1}$ ), the amide II band at $1537 \mathrm{~cm}^{-1}$, and the region between 970 and $600 \mathrm{~cm}^{-1}$ which corresponds to $\mathrm{C}-\mathrm{H}$ benzene ring bending and $-\mathrm{C}-\mathrm{H}_{2}$ skeletal deformation.
Table 1 Vibrational band assignment in the FTIR spectra reported in Fig. 2

\begin{tabular}{|c|c|}
\hline Wave number $\left(\mathrm{cm}^{-1}\right)$ & Assignment \\
\hline $3664-3430$ & $\vee \mathrm{N}-\mathrm{H}$ (non $\mathrm{H}$-bonded) \\
\hline 3286 & $\vee \mathrm{N}-\mathrm{H}(\mathrm{H}$-bonded $)$ \\
\hline $3191-3012$ & $\vee \mathrm{C}-\mathrm{H}$ (aromatic ring) \\
\hline 2971 & $\mathrm{v}_{\mathrm{a}} \mathrm{C}-\mathrm{H}_{3}$ \\
\hline 2931 & $\mathrm{v}_{\mathrm{a}} \mathrm{C}-\mathrm{H}_{2}$ \\
\hline 2869 & $\mathrm{~V}_{\mathrm{s}} \mathrm{C}-\mathrm{H}_{3}$ \\
\hline 1731 & $\vee \mathrm{O}=\mathrm{C}$ (ester, $\mathrm{PVAc})$ \\
\hline 1671 & $\begin{array}{l}\vee \mathrm{O}=\mathrm{C} \text { (monodentate urea disordered } \\
\quad \mathrm{H} \text {-bonded) }\end{array}$ \\
\hline 1641 & $\vee \mathrm{O}=\mathrm{C}$ (urea strongly $\mathrm{H}$-bonded) \\
\hline 1592 & $\vee C=C$ (aromatic ring) \\
\hline 1535 & $\delta \mathrm{O}=\mathrm{C}-\mathrm{N}-\mathrm{H} ; \vee \mathrm{O}=\mathrm{C}-\mathrm{N}-\mathrm{H}$ \\
\hline 1504 & $v-\mathrm{N}=\mathrm{N}-(\beta-n a p h t h o l)$ \\
\hline 1477 & $\delta \mathrm{C}-\mathrm{H}_{2}$ \\
\hline 1442 & $\delta_{\mathrm{a}} \mathrm{C}-\mathrm{H}_{3}$ \\
\hline 1411 & Trimer formation band (isocyanurate ring) \\
\hline 1373 & $\delta_{\mathrm{S}} \mathrm{C}-\mathrm{H}_{3}$ \\
\hline 1338 & $\omega \mathrm{C}-\mathrm{H}_{2}$ \\
\hline 1294,1226 & $\vee C-N$ \\
\hline 1093 & $\mathrm{~V}_{\mathrm{a}} \mathrm{C}-\mathrm{O}-\mathrm{C}$ (polyether-based polyol) \\
\hline 1018 & $\vee \mathrm{C}-\mathrm{O}-\mathrm{H}$ \\
\hline 939 & $\rho \mathrm{C}-\mathrm{H}_{3}$ \\
\hline $892,885,867,813$ & $\omega \mathrm{C}-\mathrm{H}$ (aromatic ring) \\
\hline 794 & $\rho C-H(P \vee A c)$ \\
\hline $750,709,669$ & $\delta \mathrm{C}-\mathrm{H}$ (aromatic ring) \\
\hline
\end{tabular}

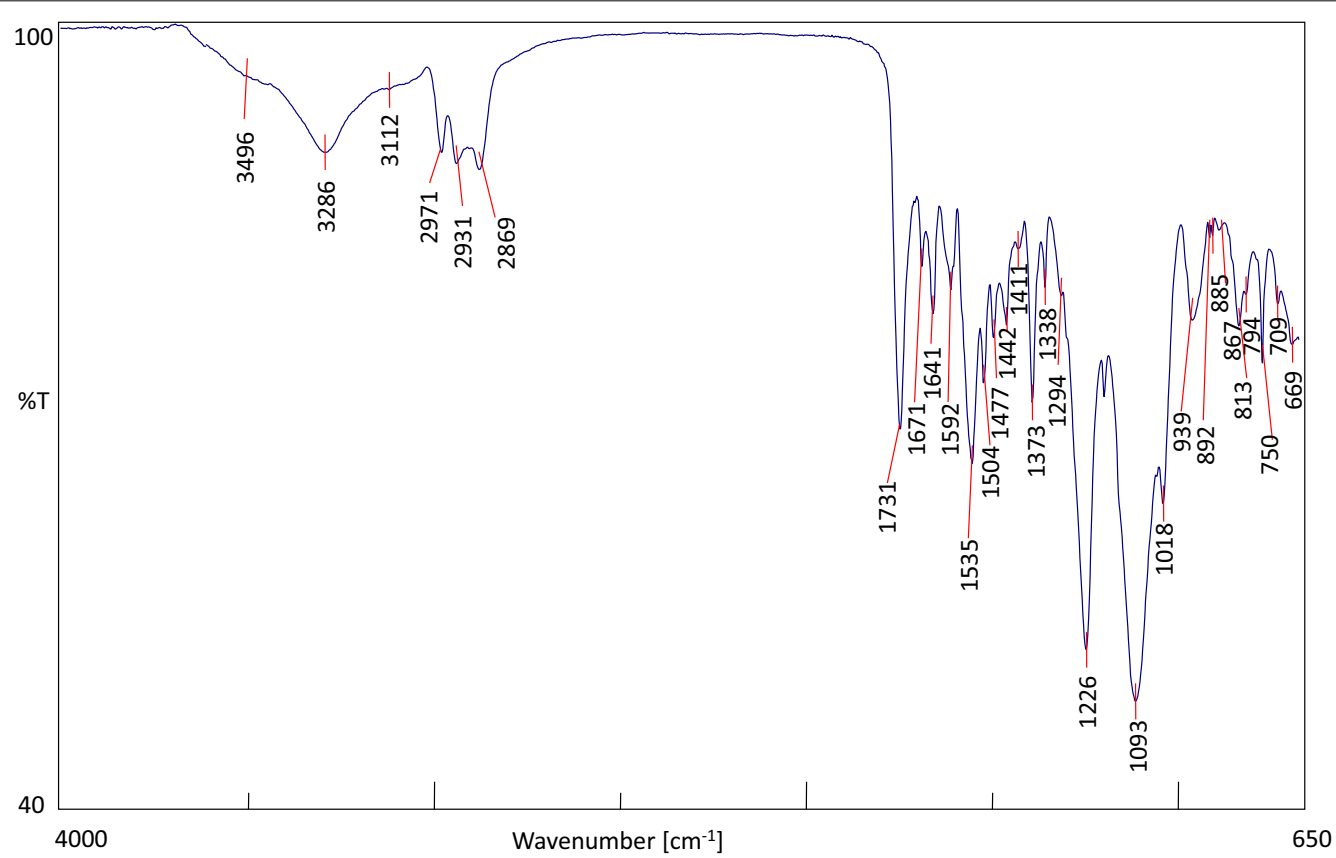

Fig. 2 ATR-FTIR spectrum obtained for the sample from "Disgelo". The band assignments are reported in Table 1 
In addition to the bands derived from the PU foam, an $\mathrm{N}=\mathrm{N}$-stretching band was observed at $1504 \mathrm{~cm}^{-1}$ [45], which is characteristic of the structure of mono-azo and $\beta$-naphthol pigments [46].

\section{EGA-MS}

Figure 3 shows the EGA-MS profile obtained for the sample from "Disgelo" together with the average mass spectra obtained for the four thermal degradation peaks identified. The thermogram shows four main thermal degradation zones: zone 1 corresponds to the temperature range $200-290{ }^{\circ} \mathrm{C}$, zone $2: 290-320^{\circ} \mathrm{C}$, zone $3: 320-$ $360^{\circ} \mathrm{C}$, and zone $4: 360-530^{\circ} \mathrm{C}$. On the basis of the mass spectra, the first thermal degradation step (zone 1) corresponds to the desorption of additives, plasticizers and to the first depolymerisation step of the polyurethane linkage, forming diisocyanates species $\left(250-300{ }^{\circ} \mathrm{C}\right)$ [20]. The most abundant ions in the mass spectra of this EGA peak are fragments with $\mathrm{m} / \mathrm{z} 174,148,145$ which correspond to 2,6-toluene diisocyanate, and fragments with $\mathrm{m} / \mathrm{z} 149$, 121, 132, 93 which correspond to phthalates [47]. The second and the third thermal degradation steps (zones 2 and 3) may be related to the pyrolysis of the polymeric network [48]. The most abundant ions in the corresponding mass spectra are fragments with $\mathrm{m} / \mathrm{z} 99,82,67,55$, related to cyclohexene and hexenol structures, such as chain extenders in the PU network and rearrangement pyrolysis products. The spectrum corresponding to the last thermal degradation step (zone 4) is more complex, and can be related to the complete thermal degradation of the polymeric network ( $\mathrm{m} / \mathrm{z} 117,101,87,73,59)$. On the basis of the EGA profile, we selected four temperatures to perform multi-shot Py-GC/MS analysis: 260, 308,340 and $600{ }^{\circ} \mathrm{C}$, respectively.

\section{Py-GC/MS}

Figure 4 shows the Py-GC/MS chromatogram obtained for the first pyrolysis shot at $260{ }^{\circ} \mathrm{C}$. The peak assignments are listed in Table 2. The most abundant species desorbed at $260{ }^{\circ} \mathrm{C}$ are diethyl phthalate (peak 8), diisobutyl phthalate (peak 11), and dibutyl phthalate (peak 14, main peak in the chromatogram). These species are commonly used as plasticizers in the production of plastic formulations. The analysis enabled us to identify the presence of 2,6-diisocyanate toluene (peak 1 ) $[38,49,50]$, one of the precursors used in the synthesis of the polyurethane foam, and its rearrangement derivatives 2-amino-6-isocyanato toluene (peak 2). In addition, the pyrolytic profile obtained for the first thermal zone features the presence of 2-naphthol (peak 5), possibly related to $\beta$-naphthol pigments $[16,51]$.

Figure 5 shows the Py-GC/MS chromatograms obtained for thermal zones 2 and 3, obtained at $308^{\circ} \mathrm{C}$ and $340{ }^{\circ} \mathrm{C}$, respectively. The two chromatographic profiles have many peaks in common, but with different relative abundances. The species identified are listed in Table 3.

The most abundant species in the pyrogram obtained at $308{ }^{\circ} \mathrm{C}$ (second shot, Fig. 5a) are 2,6-diisocyanatotoluene (peak 3), 2-amino-6-isocyanato toluene (peak 5), and hexamethylene diisocyanate (HDI -1,6-diisocyanatohexane-peak 4). Hexamethylene diisocyanate can be identified as a second diisocyanate precursor besides the already mentioned 2,6-diisocyanate toluene, thus highlighting the complexity of the formulation. A series of different chain length ether oligomers $(\mathrm{m} / \mathrm{z} 175,117$, $103,87,73,59)$ are also present, derived from the thermal degradation of the polyether component. Interpretation of the pyrolytic profile corresponding to the second shot enabled us to identify the PU as a polyether-based polyurethane produced by the polyaddition of 2,6-diisocyanate toluene, hexamethylene diisocyanate and polypropylene glycol. The result obtained by pyrolysis-GC/MS confirms that the second thermal zone is mainly related to the thermal degradation of the polymeric network.

The main peaks of the pyrogram obtained at $340{ }^{\circ} \mathrm{C}$ (third shot, Fig. 5b) are due to the thermal degradation products of the organic pigments used to colour the foam. The most abundant peak in the chromatogram corresponds to 2,4-dinitroaniline (peak 17), and the other significant pyrolysis products attributable to organic pigments are the above mentioned 2-naphthol (peak 8), 2-chloroaniline (peak 1), 2-chlorophenyl isocyanate (peak 2), and 4-chloro-2-nitroaniline (peak 12) [51]. These markers are typical of a mixture of $\beta$-naphthol and mono-azo pigments [51].

At higher temperatures, ether oligomers (peaks 21 $21, \mathrm{~m} / \mathrm{z} 175,117,103,87,73,59)$ are still produced, as proved by their identification in the pyrogram related to the third shot. Several other minor compounds related to the partial pyrolysis of the PU polymeric network were also detected.

Finally, Fig. 6 shows the pyrogram obtained by performing the last pyrolysis step at $600^{\circ} \mathrm{C}$ (fourth shot), and the thermal degradation products identified are listed in Table 4 . The pyrolysis profiles show molecules indicative of a polyvinyl acetate polymer: benzene (peak 4), styrene (peak 11), indene (peak 20), 1,2-dihydronaphthalene (peak 22), naphthalene (peak 23), 2-methylnaphthalene (peak 25), 1-methylnaphthalene (peak 26), and biphenyl (peak 29) [16]. The results enabled us to identify that the artist used a vinyl-based paint.

Oligomers of the polyether-based polyol used in the synthesis of the PU foam, chain extenders such as 5-hexen-1-ol, and cyclohexene and diisocyanate precursors were also abundant in the pyrogram [15]. As for the 

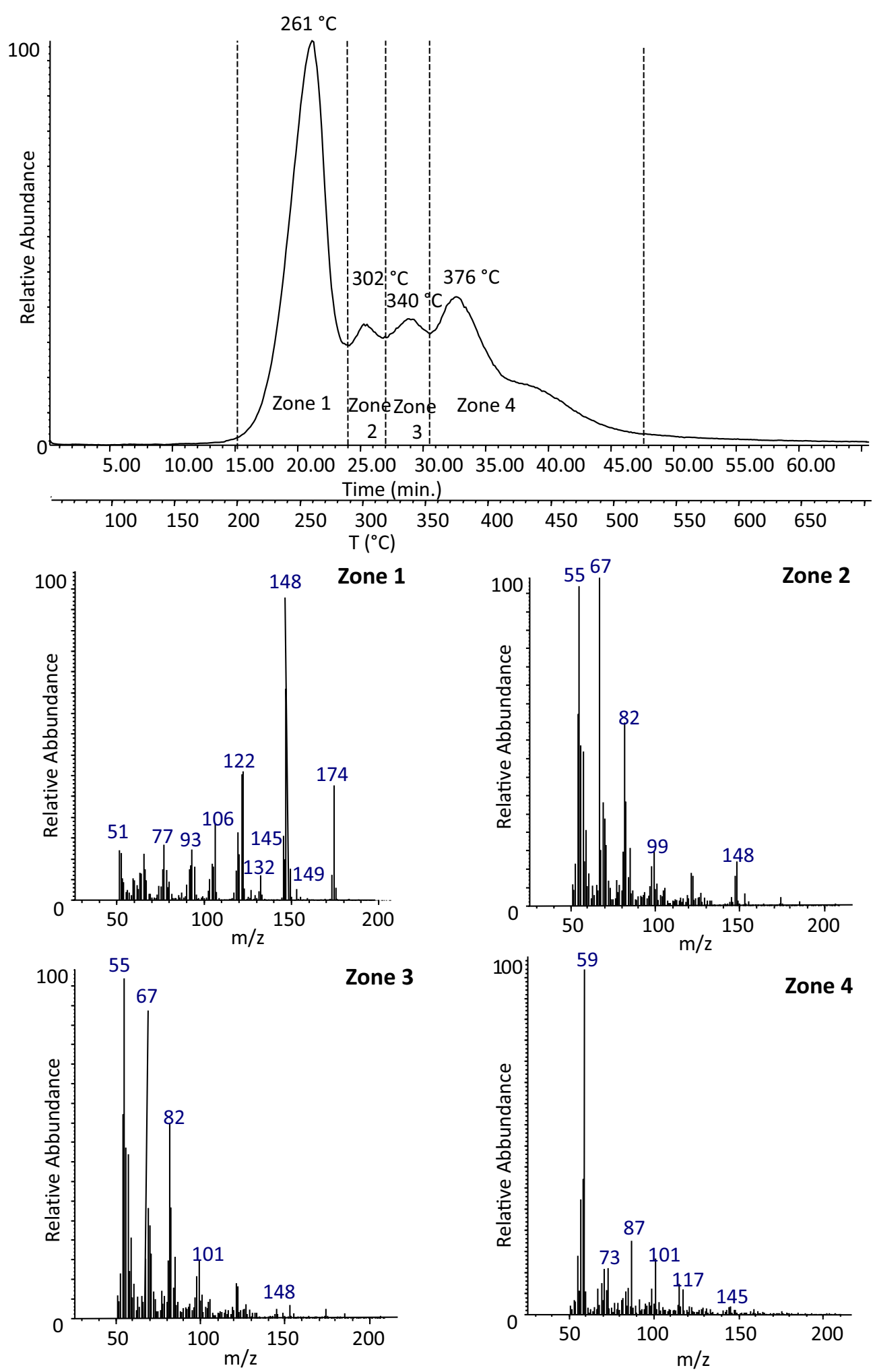

Fig. 3 EGA-MS curve obtained for the sample from "Disgelo" together with the mass spectra obtained for each thermal zone 


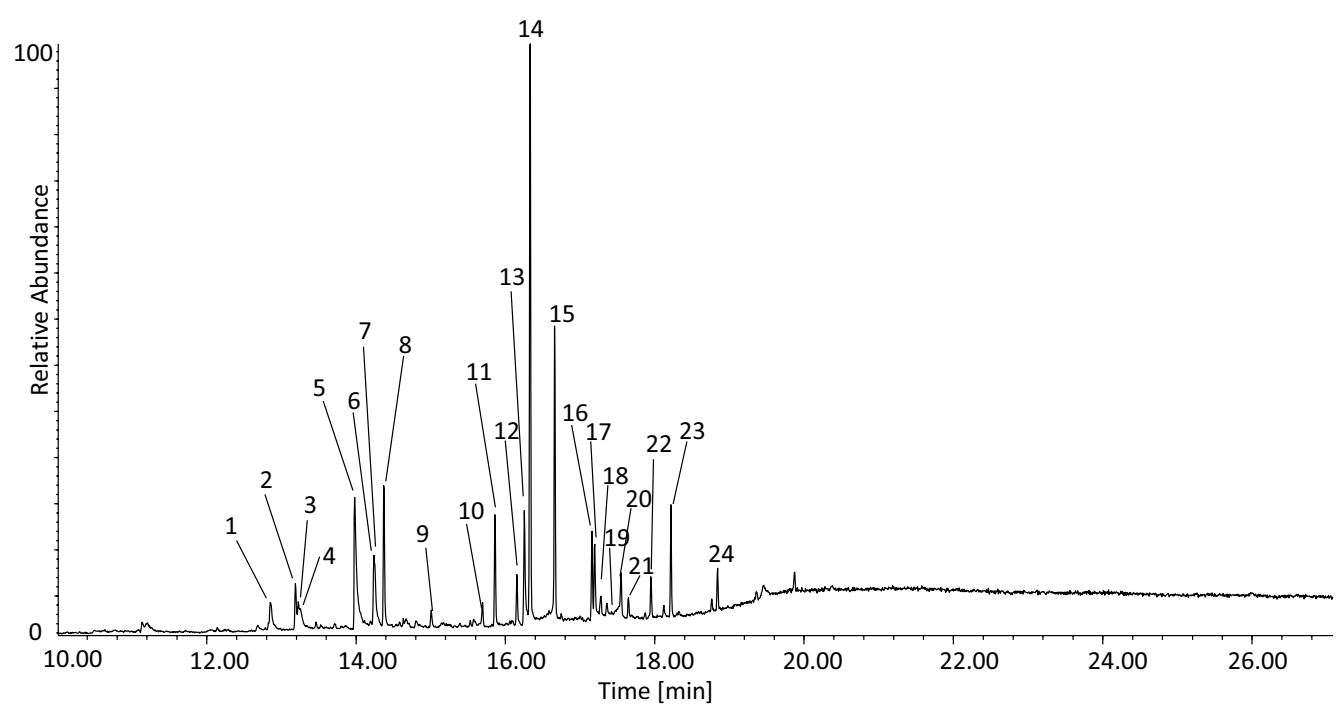

Fig. 4 First-shot pyrogram at $260^{\circ} \mathrm{C}$ obtained for the sample from "Disgelo"

Table 2 Identification of peaks in the first-shot pyrogram $\left(260^{\circ} \mathrm{C}\right)$ for the sample from "Disgelo" shown in Fig. 4 (italics: base peak ion)

\begin{tabular}{|c|c|c|}
\hline No & Peak identification & Main ions $(\mathrm{m} / \mathrm{z})$ \\
\hline 1 & 2,6-Diisocyanatotoluene & $174,145,118,91,76,64$ \\
\hline 2 & 2-Amino-6-isocyanato toluene & $148,120,106,93,65,52$ \\
\hline 3 & Isomer of 2-amino-6-isocyanato toluene & $148,119,106,92,65,52$ \\
\hline 4 & Isomer of 2-amino-6-isocyanato toluene & $148,119,106,93,65,52$ \\
\hline 5 & 2-Naphthol & $144,115,89,74,63$ \\
\hline 6 & 2-Naphthol trimethylsilyl ether & $216,201,185,145,115,73$ \\
\hline 7 & 1-Chloro-2,5-dinitrobenzene & $202,110,75$ \\
\hline 8 & Diethyl phthalate & $177,149,105,76,65$ \\
\hline 9 & Unknown & $254,239,224,99,81,69,55$ \\
\hline 10 & Tetradecanoic acid, trimethylsilyl ester & $285,145,129,117,73,55$ \\
\hline 11 & Diisobutyl phthalate & $223,149,104,76,57$ \\
\hline 12 & 7,9-Di-tert-butyl-1-oxaspiro[4.5]deca-6,9-diene-2,8-dione & $261,217,205,189,175,91,77,57$ \\
\hline 13 & Hexadecanoic acid (palmitic acid) & $256,213,129,115,97,83,73,60$ \\
\hline 14 & Dibutyl phthalate & $149,104,76$ \\
\hline 15 & Hexadecanoic acid, trimethylsilyl ester & $313,145,132,129,117,73,55$ \\
\hline 16 & Cyclohexyl acrylate & $82,67,55$ \\
\hline 17 & Octadecanoic acid & $284,241,185,129,97,73,57$ \\
\hline 18 & 3-(4-Methoxyphenyl)-2-propenoic acid & $178,161,133,121,89$ \\
\hline 19 & 1-(Phenylmethoxy)-naphthalene & $234,115,91,65$ \\
\hline 20 & Octadecanoic acid, trimethylsilyl ester & $341,145,132,117,73,55$ \\
\hline 21 & Tributyl acetylcitrate & $259,185,157,139,129,57$ \\
\hline 22 & 2-propenoic acid, 3-(4-methoxyphenyl)-, ethylhexyl ester & $178,161,133,118,90,77$ \\
\hline 23 & Hexanedioic acid, dioctyl ester & $241,147,129,112,101,83,70,57$ \\
\hline 24 & Bis(2-ethylhexyl) phthalate & $279,167,149,104,70,57$ \\
\hline
\end{tabular}



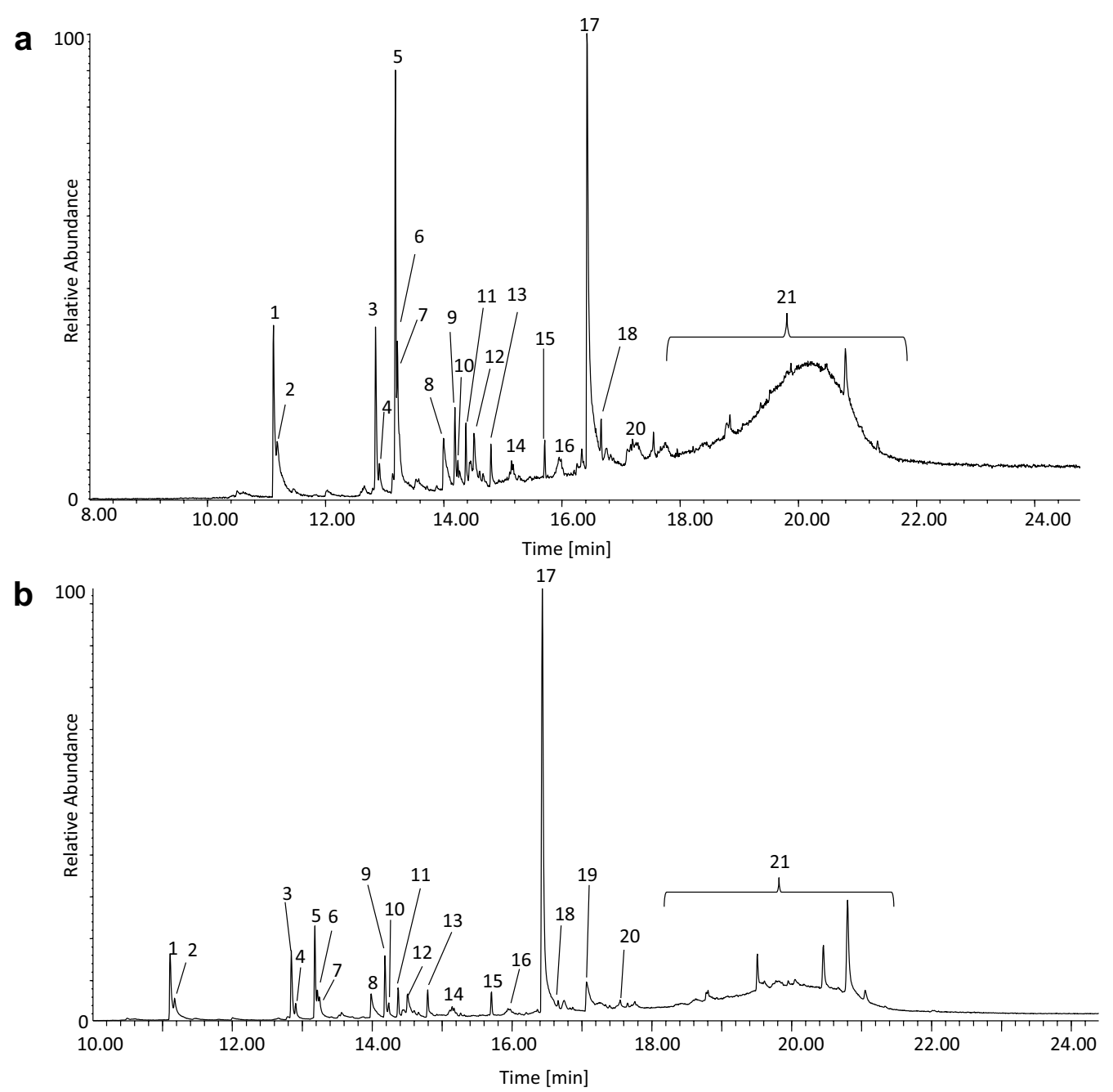

Fig. 5 Second and third shots pyrograms at $308^{\circ} \mathrm{C}$ (a) and $340{ }^{\circ} \mathrm{C}$ (b) obtained for the sample from "Disgelo"

third and fourth shots, we identified a series of ether oligomer peaks derived from the complete thermal degradation of the polymeric network ( $\mathrm{m} / \mathrm{z} 117,101,87,73$, 59 , chromatographic peaks $36,38,39,41,42$ ).

\section{HPLC-DAD and HPLC-ESI-Q-ToF}

HPLC-DAD analysis was carried out not only for confirming the hypothesis about the chemical class of the SOPs suggested by pyrolysis results, but also for unambiguously identifying the specific pigment(s) present in the paint. HPLC-ESI-Q-ToF selectivity and sensitivity were also exploited to detect minor coloured components. Figure 7 shows the HPLC-DAD chromatogram obtained at $450 \mathrm{~nm}$ from the sample extract, and the extracted ion chromatograms relating to the identified pigments.

Comparison with the reference materials, UVVis spectra from the literature, high resolution mass spectra, and tandem mass spectra interpretation revealed the composition of the colour. The paint contained a mixture of two $\beta$-naphthols (PO5 and PR1) and two monoazo pigments (PY1 and PY3) characterized by orange, red and yellow hues, employed to paint the polyurethane foam of the flower petals. In particular, PO5, PR1 and PY3 were detected in the HPLC-DAD chromatogram (see Fig. 7). PY1 (molecular ion $[\mathrm{M}-\mathrm{H}]^{-}$at $\mathrm{m} / \mathrm{z}=339.199$ ) was detected by HPLC-ESI-Q-ToF only, due to its lower concentration with respect to the other pigments, thanks to the high selectivity and sensitivity of the mass spectrometric analyser. PR1 (C.I. 12070) and PO5 (C.I. 12075) are amongst the most significant $\beta$-naphthols, which were first put on the market in 1885 and 1909, respectively. PY1 (C.I. 11680, patented in 1909) and PY3 (C.I. 11710) belong to the very common class of Hansa Yellows. 
Table 3 Identification of the peaks in the second- and third-shot pyrograms shown in Fig. 5a, b (italics: base peak ion)

\begin{tabular}{lll}
\hline No & Peak identification & Main ions (m/z) \\
\hline 1 & 2-Chloroaniline & $127,102,92,65$ \\
2 & 2-Chlorophenyl isocyanate & $153,125,90,63$ \\
3 & 2,6-Diisocyanatotoluene & $174,145,118,91,76,64$ \\
4 & 1,6-Diisocyanatohexane & $99,85,69,56$ \\
5 & 2-Amino-6-isocyanato toluene & $148,120,106,93,65,52$ \\
6 & Isomer of 2-amino-6-isocyanato toluene & $148,119,106,93,65,52$ \\
7 & Isomer of 2-amino-6-isocyanato toluene & $148,119,106,93,65,52$ \\
8 & 2-Naphthol & $144,115,89,74,63$ \\
9 & Benz(c,d)indol-2(1H)-one & $169,141,114,87,63$ \\
10 & 2-Naphthol trimethylsilyl ether & $216,201,185,145,127,115,100,73$ \\
11 & Diethyl phthalate & $177,149,105,76,65$ \\
12 & 4-Chloro-2-nitroaniline & $172,142,126,114,99,90,63,52$ \\
13 & Unknown & $183,154,128,114,88,75,63$ \\
14 & Tripropylene glycol 5 & $161,117,103,72,59$ \\
15 & Unknown & $231,215,200,185,158,130,115,103,73$ \\
16 & Tripropylene glycol 6 & $117,87,73,59$ \\
17 & 2,4-dinitroaniline & $183,153,107,91,79,63,52$ \\
18 & Hexadecanoic acid, trimethylsilyl ester & $313,145,132,129,117,73,55$ \\
19 & Benzopyridine & $185,129,102,76,63,51$ \\
20 & Octadecanoic acid, trimethylsilyl ester & $341,145,132,117,73,55$ \\
21 & Ether oligomers & $175,117,103,87,73,59$
\end{tabular}

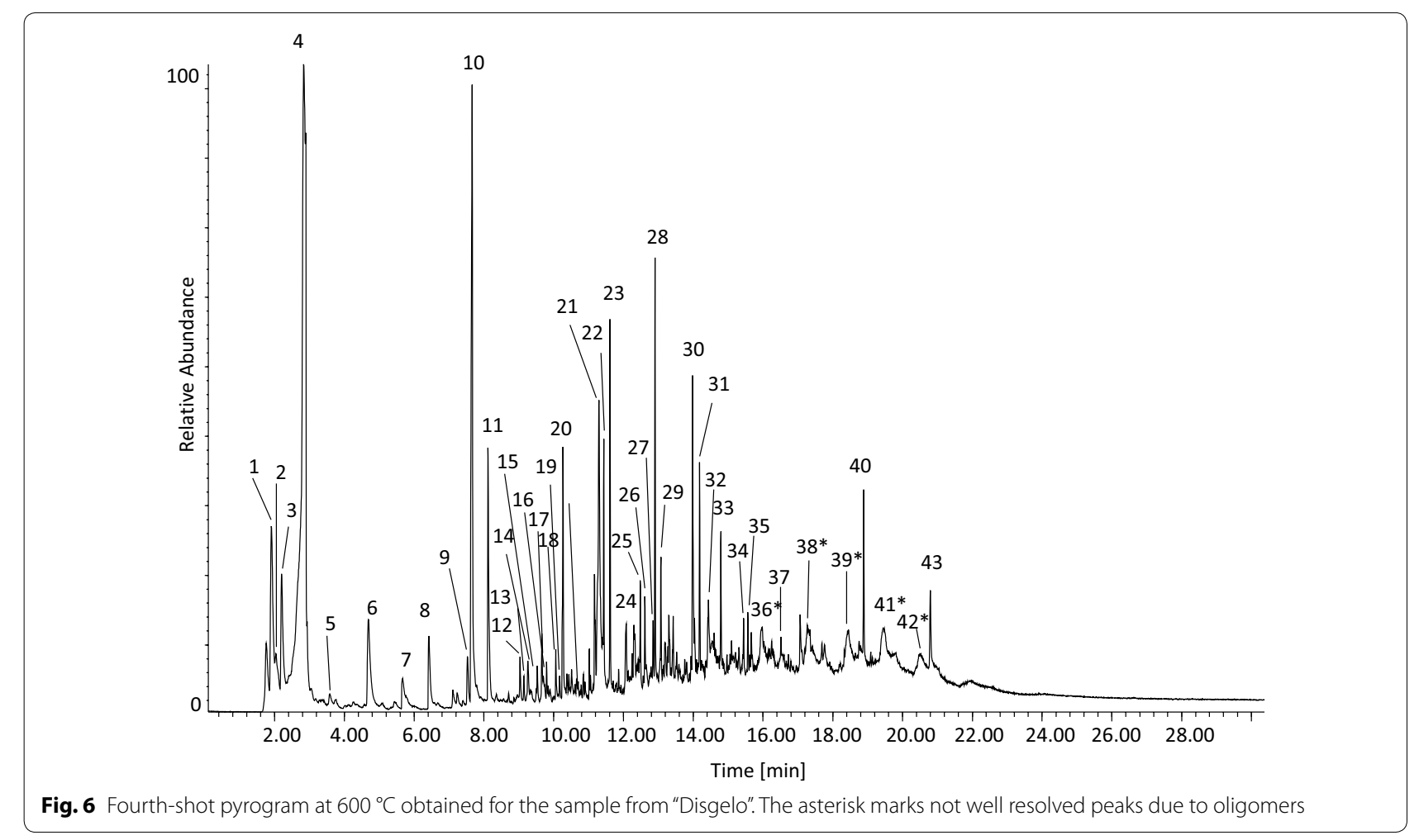


Table 4 Identification of peaks in the fourth-shot pyrogram shown in Fig. 6 (italics: base peak ion)

\begin{tabular}{|c|c|c|}
\hline No & Peak identification & Main ions $(\mathrm{m} / \mathrm{z})$ \\
\hline 1 & Acetone & 58 \\
\hline 2 & 1,3-Cyclopentadiene & 66 \\
\hline 3 & 1,5-Hexadiene & $81,67,54$ \\
\hline 4 & Benzene & $78,63,51$ \\
\hline 5 & Acetic acid & 60 \\
\hline 6 & Toluene & $91,65,51$ \\
\hline 7 & $\mathrm{~N}$-ethylacetamide & 87 \\
\hline 8 & Diethylamine & 73,57 \\
\hline 9 & Ethylbenzene & 106,91 \\
\hline 10 & 5-Hexen-1-ol & $82,67,54$ \\
\hline 11 & Styrene & $104,78,63,51$ \\
\hline 12 & Allylbenzene & $117,103,91,77,65$ \\
\hline 13 & N-propylbenzene & $120,105,91$ \\
\hline 14 & Benzaldehyde & $105,77,51$ \\
\hline 15 & (1-Methylethenyl)-benzene & $118,103,91,78,63,51$ \\
\hline 16 & Allylbenzene isomer & $117,103,91,65,51$ \\
\hline 17 & Cyclohexene & $82,67,54$ \\
\hline 18 & 1-Ethenyl-2-methyl-benzene & $117,103,91,73,63,51$ \\
\hline 19 & Allylbenzene isomer & $117,103,91,77,63,51$ \\
\hline 20 & Indene & $115,89,63,51$ \\
\hline 21 & 1-Butynyl-benzene & $130,115,102$ \\
\hline 22 & 1,2-dihydronaphthalene & $130,115,102,77,67,51$ \\
\hline 23 & Naphthalene & $128,102,74,63,51$ \\
\hline 24 & 1,2-Dihydro-2-methyl-naphthalene & $144,129,115$ \\
\hline 25 & 2-Methylnaphthalene & $142,115,89,74,63,51$ \\
\hline 26 & 1-Methylnaphthalene & $142,115,89,74,63,51$ \\
\hline 27 & 2,6-Diisocyanatotoluene & $174,145,132,118,91,76$ \\
\hline 28 & 1,6-Diisocyanatohexane & $99,85,69,56$ \\
\hline 29 & Biphenyl & $154,76,51$ \\
\hline 30 & 2-Naphthol & $144,115,89,63$ \\
\hline 31 & Unknown & $169,141,114,88,74,63$ \\
\hline 32 & Unknown & $144,115,103,89,73,59$ \\
\hline 33 & Unknown & $183,154,128,114,88,63$ \\
\hline 34 & 1,2-Dihydrophenanthrene & $180,165,152,89,76$ \\
\hline 35 & Phenanthrene & $178,152,89,76,63$ \\
\hline 36 & Oligomer & $117,103,87,73,59$ \\
\hline 37 & 2-Phenylnaphthalene & $204,115,101$ \\
\hline 38 & Oligomer & $202,117,101,87,73,59$ \\
\hline 39 & Oligomer & $175,117,101,87,73,59$ \\
\hline 40 & Unknown & $261,232,204,129,102,77$ \\
\hline 41 & Oligomer & $207,117,101,87,73,59$ \\
\hline 42 & Oligomer & $281,207,101,87,73,59$ \\
\hline 43 & Unknown & $306,128,115,101,89,77$ \\
\hline
\end{tabular}

\section{Conclusions}

The multianalytical approach enabled us to characterize in detail, at a molecular level, a complex sample from a three-dimensional work of art made up of different synthetic materials: polyurethane foam painted with a vinyl paint containing organic pigments. Non-destructive ATR-FTIR allowed us to identify the main constituents of the sample as a polyether-based polyurethane foam. EGA-MS analysis provided both thermal and chemical information in one analytical run, so that we could select four temperatures to be used in multi-shot Py-GC/ MS analysis and thus to selectively study the different fractions evolved at different temperatures. Multi-shot Py-GC/MS was needed not only to obtain more specific information on the chemical composition of the PU and to identify the precursors used in its synthesis, but also to characterise the paint applied on the foam. Information on the various components of the mixture was obtained, including additives and organic pigments, separating them on the basis of their different thermal degradation temperatures. Specifically:

- In the pyrogram corresponding to the first shot $\left(260{ }^{\circ} \mathrm{C}\right)$, the additives used in the formulations of the synthetic materials employed by the artist were detected: diethyl phthalate, diisobutyl phthalate, and dibutyl phthalate;

- The peaks detected in the second shot at $308^{\circ} \mathrm{C}$ characterized the PU used by the artist as a polyetherbased polyurethane produced by the polyaddition of 2,6-diisocyanate toluene, hexamethylene diisocyanate and polypropylene glycol;

- The pyrolysis products of synthetic organic pigments were produced during the third shot $\left(340{ }^{\circ} \mathrm{C}\right)$, and the markers typical of a mixture of $\beta$-naphthol and mono-azo pigments were detected in the pyrogram;

- The last pyrogram obtained at $600{ }^{\circ} \mathrm{C}$ contained the molecular markers of a polyvinyl acetate resin, which was identified as the paint binder.

HPLC-DAD and HPLC-ESI-MS analyses confirmed the identification of $\beta$-naphthol and mono-azo pigments, and provided a positive identification of two $\beta$-naphthols (PO5 and PR1) and two monoazo pigments (PY1 and PY3).

This case study represents the first application of EGAMS complemented by multi-shot Py-GC/MS to a painted plastic sculpture, and serves as a proof-of concept in demonstrating how the approach is unique in resolving complex mixtures of polymers, pigments and additives without any sample pretreatment.

Evaluating the relative amounts of compounds produced during thermal degradation also provided 


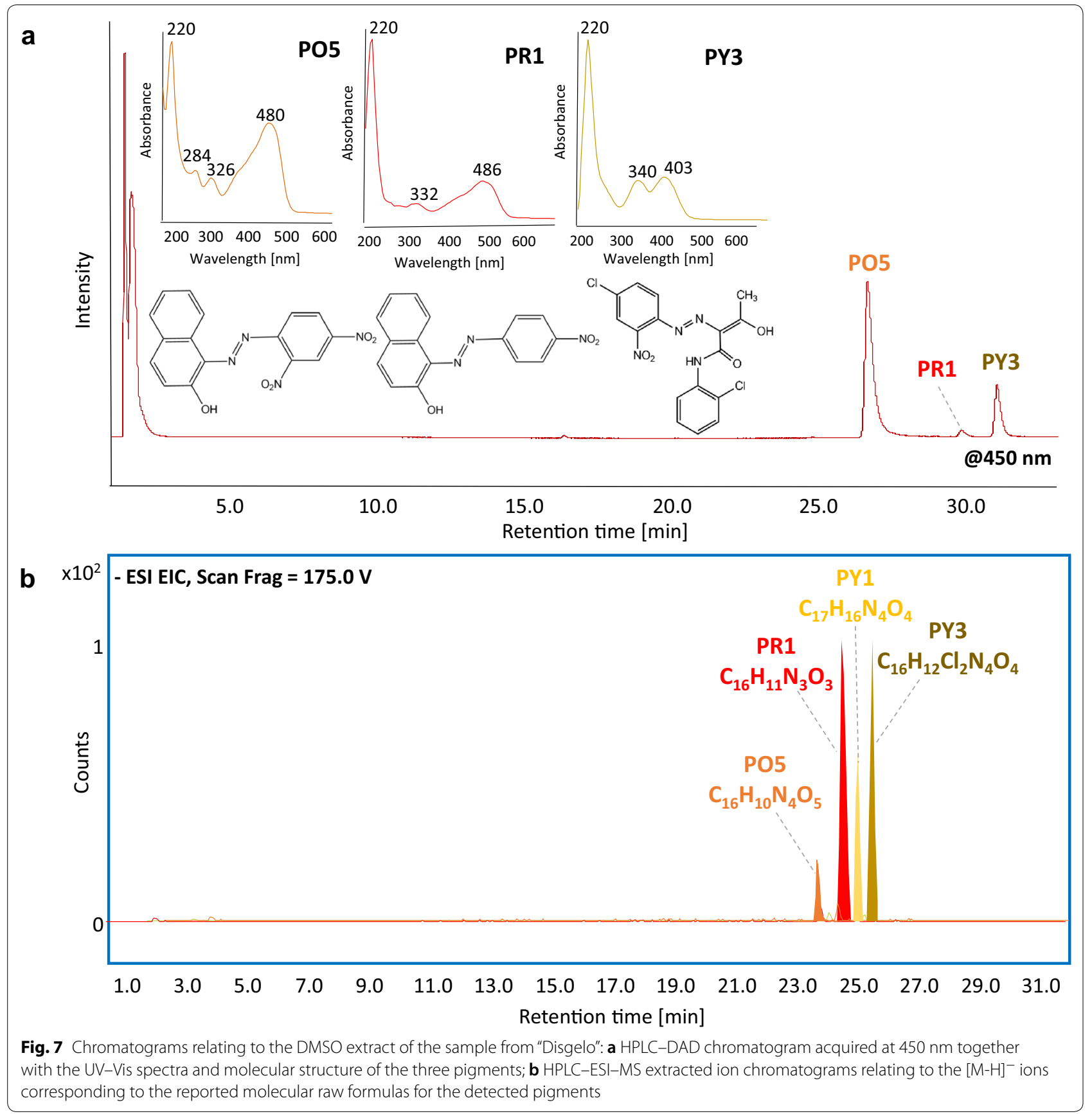

semi-quantitative information, thus proving the approach extremely valuable in future studies on the degradation of materials.

\section{Authors' contributions}

FM managed the research project. FM and JLN designed the experiments. $J L N$ and GB and FS performed the analyses. JLN, GB, FS, ID and FM performed the data analysis and interpretation. JLN, FS, ID and FM wrote the manuscript. All the authors contributed to the discussion of the results and reviewed the manuscript. All authors read and approved the final manuscript.

\section{Acknowledgements}

The authors would like to thank the conservator Antonio Rava. Antonella Manariti is also acknowledged for her technical assistance.

\section{Competing interests}

The authors declare that they have no competing interests.

\section{Availability of data and materials}

On request, the authors will gladly share other additional files and data not published in the article. 


\section{Funding}

This research was not supported or funded by any specific grant. University of Pisa provided the equipment, the infrastructure and the human resources, including Francesca Sabatini's PhD scholarship.

\section{Publisher's Note}

Springer Nature remains neutral with regard to jurisdictional claims in published maps and institutional affiliations.

Received: 13 November 2018 Accepted: 5 February 2019

Published online: 16 February 2019

\section{References}

1. van Oosten T, Shashoua Y, Waentig F, Fachhochschule K. Fachbereich Restaurierung und Konservierung von Kunst- und, I.C.f. Conservation, G. Modern Materials Working, Plastics in art: history, technology, preservation, Siegl, München.

2. Shashoua Y. Conservation of plastics: materials science, degradation and preservation. 2016.

3. Langhals $\mathrm{H}$. Color chemistry. Synthesis, properties and applications of organic dyes and pigments. Angew Chem Int Ed. 2004;43:5291-2.

4. Sabatini F, Giugliano R, Degano I. Photo-oxidation processes of Rhodamine B: a chromatographic and mass spectrometric approach. Microchem J. 2018;140:114-22.

5. Lech K, Wilicka E, Witowska-Jarosz J, Jarosz M. Early synthetic dyesa challenge for tandem mass spectrometry. J Mass Spectrom. 2013:48:141-7.

6. Lazzari M, Ledo-Suárez A, López T, Scalarone D, López-Quintela MA. Plastic matters: an analytical procedure to evaluate the degradability of contemporary works of art. Anal Bioanal Chem. 2011;399:2939-48.

7. Saviello D, Pouyet E, Toniolo L, Cotte M, Nevin A. Synchrotron-based FTIR microspectroscopy for the mapping of photo-oxidation and additives in acrylonitrile-butadiene-styrene model samples and historical objects. Anal Chim Acta. 2014;843:59-72.

8. Manfredi M, Barberis E, Marengo E. Prediction and classification of the degradation state of plastic materials used in modern and contemporary art. Appl Phys A. 2017;123:35.

9. Morales Muñoz C. Surface modification of plasticized PVC by dry cleaning methods: consequences for artworks. Appl Surf Sci. 2010;256:3567-72.

10. Saviello D, Andena L, Gastaldi D, Toniolo L, Goidanich S. Multi-analytical approach for the morphological, molecular, and mechanical characterization after photo-oxidation of polymers used in artworks. J Appl Polym Sci. 2018;135:46194.

11. Carlesi S, Ricci M, Cucci C, Nasa JL, Lofrumento C, Picollo M, Becucci M. Multivariate analysis of combined Fourier transform near-infrared spectrometry (FT-NIR) and Raman datasets for improved discrimination of drying oils. Appl Spectrosc. 2015;69:865-76.

12. Degano I, Modugno F, Bonaduce I, Ribechini E, Colombini MP. Recent advances in analytical pyrolysis to investigate organic materials in heritage science. Angew Chem Int Ed. 2018;25:7313-23.

13. Bartolozzi G, Cucci C, Marchiafava V, Masi S, Picollo M, Grifoni E, Legnaioli S, Lorenzetti G, Pagnotta S, Palleschi V. A multidisciplinary approach to the investigation of "La Caverna dell'Antimateria"(1958-1959) by Pinot Gallizio. Herit Sci. 2014;2:29.

14. Carlesi S, Bartolozzi G, Cucci C, Marchiafava V, Picollo M, La Nasa J, Di Girolamo F, Dilillo M, Modugno F, Degano I. Discovering "The Italian Flag" by Fernando Melani (1907-1985). Spectrochim Acta Part A Mol Biomol Spectrosc. 2016;168:52-9.

15. Scalarone $D$, Chiantore O. Py-GC/MS of natural and synthetic resins. In: Colombini MP, Modugno F, editors. Organic mass spectrometry in art and archaeology. Hoboken: Wiley; 2009. p. 327-61.

16. Ghelardi E, Degano I, Colombini MP, Mazurek J, Schilling M, Learner T. Py-GC/MS applied to the analysis of synthetic organic pigments: characterization and identification in paint samples. Anal Bioanal Chem. 2015;407:1415-31.

17. La Nasa J, Di Marco F, Bernazzani L, Duce C, Spepi A, Ubaldi V, Degano I, Orsini S, Legnaioli S, Tiné M. Aquazol as a binder for retouching paints.
An evaluation through analytical pyrolysis and thermal analysis. Polym Degrad Stab. 2017;144:508-19.

18. La Nasa J, Orsini S, Degano I, Rava A, Modugno F, Colombini MP. A chemical study of organic materials in three murals by Keith Haring: a comparison of painting techniques. Microchem J. 2016;124:940-8.

19. Orsini S, La Nasa J, Modugno F, Colombini M. Characterization of Aquazol polymers using techniques based on pyrolysis and mass spectrometry. J Anal Appl Pyrol. 2013;104:218-25.

20. Wei S, Pintus V, Schreiner M. Photochemical degradation study of polyvinyl acetate paints used in artworks by Py-GC/MS. J Anal Appl Pyrol. 2012;97:158-63.

21. Wei S, Pintus V, Schreiner M. A comparison study of alkyd resin used in art works by Py-GC/MS and GC/MS: the influence of aging. J Anal Appl Pyrol. 2013:104:441-7.

22. Scalarone $D$, Chiantore $O$. Separation techniques for the analysis of artists acrylic emulsion paints. J Sep Sci. 2004;27:263-74.

23. Ceccarini A, Corti A, Erba F, Modugno F, La Nasa J, Bianchi S, Castelvetro V. The hidden microplastics: new Insights and figures from the thorough separation and characterization of microplastics and of their degradation byproducts in coastal sediments. Environ Sci Technol. 2018:52:5634-43.

24. Ghelardi E, Degano I, Colombini MP, Mazurek J, Schilling M, Khanjian H, Learner T. A multi-analytical study on the photochemical degradation of synthetic organic pigments. Dyes Pigm. 2015;123:396-403.

25. de Keijzer M. The delight of modern organic pigment creations. In: van den Berg KJ, Burnstock A, de Keijzer M, Krueger J, Learner T, Tagle DA, Heydenreich G, editors. Issues in contemporary oil paint. Cham: Springer International Publishing; 2014. p. 45-73.

26. Degano I, Tognotti P, Kunzelman D, Modugno F. HPLC-DAD and HPLCESI-Q-ToF characterisation of early 20th century lake and organic pigments from Lefranc archives. Herit Sci. 2017;5:7.

27. Degano I, Sabatini F, Braccini C, Colombini MP. Triarylmethine dyes: characterization of isomers using integrated mass spectrometry. Dyes Pigm. 2019;160:587-96.

28. Tsuge S, Ohtani H, Watanabe C. Pyrolysis-GC/MS data book of synthetic polymers: pyrograms, thermograms and MS of pyrolyzates. Amsterdam: Elsevier; 2011.

29. La Nasa J, Biale G, Ferriani B, Colombini MP, Modugno F. A pyrolysis approach for characterizing and assessing degradation of polyurethane foam in cultural heritage objects. J Anal Appl Pyrol. 2018;134:562-72.

30. Sabatini F, Nacci T, Degano I, Colombini MP. Investigating the composition and degradation of wool through EGA/MS and Py-GC/MS. J Anal Appl Pyrol. 2018;135:111-21.

31. Tamburini D, Łucejko JJ, Ribechini E, Colombini MP. Snapshots of lignin oxidation and depolymerization in archaeological wood: an EGA-MS study. J Mass Spectrom. 2015;50:1103-13.

32. Rava A. La conservazione di opere in poliuretano espanso. II lavoro di Piero Gilardi, Kermes. 2015:98:14-22.

33. Benson LG, Muresu G, Gilardi P. An interview with Piero Gilardi. Leonardo. 1968;1:431-9.

34. van Oosten T. PUR facts: conservation of polyurethane foam in art and design. Amsterdam: Amsterdam University Press; 2015.

35. Degano I, La Nasa J. Trends in high performance liquid chromatography for cultural heritage. In: Analytical chemistry for cultural heritage. Topics in Current Chemistry Collections. Springer; 2017. p. 263-90.

36. Faraco M, Fico D, Pennetta A, De Benedetto GE. New evidences on efficacy of boronic acid-based derivatization method to identify sugars in plant material by gas chromatography-mass spectrometry. Talanta. 2016;159:40-6.

37. La Nasa J, Zanaboni M, Uldanck D, Degano I, Modugno F, Kutzke H, Tveit ES, Topalova-Casadiego B, Colombini MP. Novel application of liquid chromatography/mass spectrometry for the characterization of drying oils in art: elucidation on the composition of original paint materials used by Edvard Munch (1863-1944). Anal Chim Acta. 2015;896:177-89.

38. Watanabe C, Teraishi K, Tsuge S, Ohtani H, Hashimoto K. Development of a new pyrolyzer for thermal desorption and/or pyrolysis gas chromatography of polymeric materials. J Hihg Resolut Chromatogr. 1991;14:269-72.

39. de Sà F, Ferreira JL, Pombo Cardoso I, Macedo R, Ramos AM. Shedding new light on polyurethane degradation: Assessing foams condition in design objects. Polym Degrad Stab. 2017;144:354-65. 
40. Priester RD, McClusky JV, O’Neill RE, Turner RB, Hartcock MA, Davis BL. FT-IR - a probe into the reaction kinetics and morphology development of urethane foams. J Cell Plast. 1990;26:346-67.

41. Silverstein RM, Webster FX, Kiemle DJ. Infrared spectrometry, spectrometric identification of organic compounds. Hoboken: Wiley; 2005. p. 72-126.

42. Lan Z, Daga R, Whitehouse R, McCarthy S, Schmidt D. Structure-properties relations in flexible polyurethane foams containing a novel bio-based crosslinker. Polymer. 2014;55:2635-44.

43. Davies P, Evrard G. Accelerated ageing of polyurethanes for marine applications. Polym Degrad Stab. 2007;92:1455-64.

44. Yilgör I, Yilgör E, Wilkes GL. Critical parameters in designing segmented polyurethanes and their effect on morphology and properties: a comprehensive review. Polymer. 2015;58:1-36.

45. Ahmed F, Dewani R, Pervez MK, Mahboob SJ, Soomro SA. Non-destructive FT-IR analysis of mono azo dyes. Bul Chem Commun. 2016;1:71-7.

46. Learner T. Analysis of modern paints. Los Angeles: Getty Conservation Institute; 2004.
47. Yin P, Chen H, Liu X, Wang Q, Pan R. Mass spectral fragmentation pathways of phthalates esters by gas chromatography-tandem mass spectrometry. Anal Lett. 2014;47:1579-88.

48. Hiltz JA. Analytical pyrolysis gas chromatography/mass spectrometry (py-GC/MS) of poly(ether urethane)s, poly(ether urea)s and poly(ether urethane-urea)s. J Anal Appl Pyrol. 2015;113:248-58.

49. Ohtani H, Kimura T, Okamoto K, Tsuge S. Characterization of polyurethanes by high-resolution pyrolysis-capillary gas chromatography. J Anal Appl Pyrol. 1987;12:115-33.

50. Marshall GL. Pyrolysis-mass spectrometry of polymers II: polyurethanes. Eur Polym J. 1983;19:439-44.

51. Russel J, Singer BW, Perry JJ. The identification of synthetic organic pigments in modern paints and modern paintings using pyrolysis-gas chromatography-mass spectrometry. Anal Bioanal Chem. 2011;400:1473-91.

\section{Submit your manuscript to a SpringerOpen ${ }^{\circ}$ journal and benefit from:}

- Convenient online submission

- Rigorous peer review

- Open access: articles freely available online

- High visibility within the field

- Retaining the copyright to your article

Submit your next manuscript at $\mathbf{s p r i n g e r o p e n . c o m ~}$ 